\title{
What words really mean: examining the violent offender's thinking
}

\section{Opinion}

I often hear people say that they did not mean to say or do something, that somehow, a word or behavior just slipped out. This is beyond impossible. You first must have a thought before you speak and a thought before you act. Therefore, nothing you ever say or do was an accident. And you can never say that you "did not mean" to say or do something you did do, because you thought about it and acted. This is the cognitive reality of our behavior, and our behavior includes what we say. In addition, what we chose to not do or say was also intentional. Our behavior speaks volumes about our beliefs and morals. As an expert on sexual offenders and predators I have come to understand that the offender makes their own decision. In fact, the sexual offender made their decision to take sex, to use sex as a weapon, and to harm and at times kill their victims because of numerous factors, but one primary factor: they simply made the decision to do what they wanted to do to the victim without any regard for the victim's safety or well-being. The victim's behavior did not significantly influence the sexual offender's decision to rape, commit incest, kidnap, assault or kill.

Understanding how the offender thinks is important. Assessing someone's thoughts, morals, and values is not easy because we cannot see what is on the mind. However, the words we choose represent our beliefs, which in turn guide our behavioral choices. For example, if you believe in respecting women, then you would not belittle them, abuse them, and would never choose to rape them. In fact, you would never use terms that were derogatory, like slut and whore. When anyone uses the derogatory terms about women, they hold derogatory and degrading thoughts about women. So then a word is never just a word, it represents the thoughts and morals and beliefs of the individual. It is the thoughts and beliefs that guide our choice of behavior. If you have derogatory beliefs about women, then it would be easy for you to abuse and rape.

But make no mistake. Your choice of behavior (verbal, physical, or sexual) is always, yes always $100 \%$ under your control. No one can make you say or do things, only you choose how to react. Even when drunk, you know damn well what you are saying and doing and make decisions that only you can make. Alcohol does not ever make us do or say anything; alcohol does not cause us to behave without first thinking about what we want to do. For example, if you rape someone while you are intoxicated, you made a conscious, thought-out decision to rape. The alcohol may make it easier to ignore the consequences, but alcohol never causes you to do anything nor does alcohol prevent you from knowing what you are doing when you are doing it. While drunk, you still know right from wrong and always know what you are doing at that time. I have heard claims from rapists that they were too
Volume 2 Issue 4 - 2016

Scott A Johnson

Licensed Psychologist, USA

Correspondence: Scott Allen Johnson, Licensed Psychologist, Minneapolis, USA, Tel 6/2-269-3628, Email scott@forensicconsultation.org

Received: June 12, 2016 | Published: June 20, 2016

drunk to know what they were doing. However, they were lying. They knew damn well what they were doing.

It takes a lot of focus to engage in sexual activity. It takes a significant degree of dedication and commitment to counter resistance to rape. It also takes a considerable degree of self-righteousness and arrogance to believe that the victim deserved to be raped and that the offender goes about their life as though nothing happened. Lastly, to have sex with a person who is unable to respond verbally or physically out of fear or incapacitation (e.g., drugged, passed-out) takes significant commitment and a desire to have sex knowing that the victim is not responding to the sexual behavior. Who has sex with an unresponsive person or with a person who is being physical forced or too fearful to refuse except for a rapist. Only a rapist rapes, not the alcohol, not poor judgement, not a moral lapse. The only people who rape are those who for some time believed it was alright to rape- it was never a last minute decision. ${ }^{1}$ For more information about how alcohol impacts and does not impact rape. ${ }^{2}$

\section{Acknowledgments}

None.

\section{Conflicts of interest}

The author declares that there are no conflicts of interest.

\section{References}

1. Johnson SA. Masking a Sex Offense: When a Non-Sex Crime Really is a Sex Crime. The Forensic Examiner. 2009;18(3):46-50.

2. Johnson SA. Understanding the Role of Alcohol During Rape: The Perfect Storm of Attention, Emotion, \& Expectancies. Int J Emerg Ment Health. 2014;16(1):259-269. 